\title{
Structure and pasting properties of alkaline-treated phosphorylated cross-linked waxy maize starches
}

\begin{abstract}
The objectives of this study were to determine the stability of cross-linked bonds of starch at different $\mathrm{pH}$ values and their effects on the pasting property of waxy maize starch crosslinked by $0.05 \%$ and $3 \%$ sodium trimetaphosphate/sodium tripolyphosphate. The cross-linked waxy maize starch (CLWMS) was slurried (40\%, w/w) and subjected to alkali treatments of $\mathrm{pH} 9,10,11$, and 12 at $40{ }^{\circ} \mathrm{C}$ for $4 \mathrm{~h}$. The phosphorus in $3 \%$ CLWMS decreased with increasing $\mathrm{pH}$ and remained unchanged in $0.05 \%$ CLWMS for all $\mathrm{pH}$ treatments. Decreased settling volumes indicated the reduction of swelling power for the alkali-treated CLWMS at $\mathrm{pH} 11$ and 12. The ${ }^{31} \mathrm{P}$ NMR spectra of 3\% CLWMS at pH 12 showed decreased cyclic monostarch phosphate, monostarch monophosphate, and monostarch diphosphate, but significantly increased distarch monophosphate. Alkali treatments of phosphorylated crosslinked starches offer a way to manipulate the rheological properties of cross-linked starch for desired food applications.
\end{abstract}

Keyword: Cross-linked waxy maize starch; Starch phosphates; Structural property; Pasting property 
